\title{
Alpha-N-acetylgalactosaminidase deficiency
}

INSERM

\section{Source}

INSERM. (1999). Orphanet: an online rare disease and orphan drug data base. Alpha-Nacetylgalactosaminidase deficiency. ORPHA:3137

Alpha- $\mathrm{N}$-acetylgalactosaminidase (NAGA) deficiency is a very rare lysosomal storage disease that is clinically and pathologically heterogeneous and is characterized by deficient NAGA activity. 